Архаичные мотивы в декоре ингушских и казахских войлочных изделий: сравнительно-сопоставительный аспект

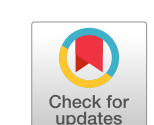

Бердникова О.Ю.

МБОУ ДО «Детская художественная школа №5»,

Институт языка, литературы и искусства им. Г. Ибрагимова,

Казань, Российская Федерация.

(iD) https://orcid.org/0000-0002-3254-1392, e-mail: berdnikovaou@yandex.ru

Резюме: В данной работе рассматриваются стилевые особенности, характерные для ингушского и казахского искусства войлока, проводятся параллели технологий изготовления, а также традиционного декора ингушских и казахских самобытных войлочных ковров. Цель работы - выявление общих исторически обусловленных стилевых особенностей в оформлении ингушских и казахских изделий из войлока. Методы. В процессе исследования мы применяли семантический и сравнительно-сопоставительный анализы с опорой на иконологический метод и теорию распознавания образов. Результаты. Гипотеза о том, что отдельные способы войлоковаляния, наиболее архаичные элементы орнамента, как и технология их создания, являются сходными в искусстве этих народов, не находящихся в условиях тесного соседства, находит подтверждение. Данные фракты свидетельствуют о соприкосновении культур их прапредков в начале Средних веков, когда на Северном Кавказе поселились гунны - выходцы из центральной Азии. Гунны, как представители историко-культурной общности Мира Степи, обладали сходной системой взглядов на жизнеустройство. В их понимании трехчастной структурой мироздания управлял Тенгри, возглавляющий пантеон богов. В декоративно-прикладном искусстве номадов он воплощался в виде солярной розетки. Автохтонное население Северного Кавказа (скифо-сарматы и сармато-аланы) поклонялись Солнцу Куару, представления о котором для гуннов Кавказа слились с образом Тенгри и зафиксировались в известных им визуальных символах, обнаруженных в декоре изделий, сопровождающих их жизнеустройство. Элементы архаичного орнамента и технологии производства, в соответствии с принципом преемственности в народном искусстве, сохранялись веками. Они составили основу стилевых особенностей современных войлочных ковров как у ингушского, так и у казахского народов.

Ключевые слова: искусство войлока, ингушские и казахские мастера, орнаментальные мотивы, устойчивые стилевые особенности.

Для цитирования: Бердникова О.Ю. Архаичные мотивы в декоре ингушских и казахских войлочных изделий: сравнительно-сопоставительный аспект // Этническая культура. - 2021. - Т. 3, № 2. - С. 6-9. DOI:10.31483/r-97476.

\title{
Archaic Motives in Décor of Ingush and Kazakh Felts: Comparative and Contrastive Aspect
}

\author{
Olga Yu. Berdnikova \\ MBEI of PE of Kazan "Child School of Art No. 5", \\ Institute of language, literature and arts named after G. Ibragimov of Tatarstan Academy of Sciences, \\ Kazan, Russian Federation. \\ https://orcid.org/0000-0002-3254-1392, e-mail: berdnikovaou@yandex.ru
}

\begin{abstract}
The following work examines stylistic peculiarities of Ingush and Kazakh felts, offers the parallels of manufacturing technology as well as traditional décor of Ingush and Kazakh original carpets. The aim of the study is to elicit mutual historically contingent stylistic features of Ingush and Kazakh felts arrangement. Methods. In the process of the study we used semantic as well as comparative and contrastive analyses aimed on iconologic method and image discrimination theory. Results. The hypothesis of different felt methods, more archaic ornament elements as well as the technology of its creation, are in fact similar in the art of these people, not being in close kinship, finds its endorsement. These facts justify juxtaposition of the cultures of their ancestors in the beginning of Middle ages when Huns - people of Central Asia decent - took up their residence in North Caucasus. Huns, being the representatives of historical and cultural commune of the barren world, possessed similar points of view on life order. In their notion the structure of the world was controlled by Tengri - the head of God's pantheon. In nomad's applied arts he was depicted as a rosette. North Caucasus indigenous population (Scythian Sarmatians and Sarmatian Alans) worshipped Kuar the Sun, the notion of whom merged with the image of Tengri and stuck in well-known visual symbols, found in decorations following their world view. The elements of archaic ornament and the manufacturing technologies in accordance with the succession principle in folk arts carried on through centuries. They formed the base of stylistic peculiarities of modern felts among both Ingush and Kazakh people.
\end{abstract}

Keywords: felt arts, Ingush and Kazakh masters, ornament motives, resilient stylistic features.

For citation: Berdnikova O.Yu. (2021). Archaic Motives in Décor of Ingush and Kazakh Felts: Comparative and Contrastive Aspect. Etnicheskaya kultura = Ethnic Culture, 3(2), 6-9. (in Russ.). DOI:10.31483/r-97476.

\section{Введение}

Войлоковаляние является составной частью декоративно-прикладного искусства у ингушского и казахского народов. В данном исследовании проводится сравнительно-сопоставительный анализ техники производства, а также декора традиционных ингушских и казахских войлочных изделий. Опираясь на полученные данные, выявляются общие устойчивые элементы оформления и раскрываются семантические значения узоров, что составляет цель работы. В связи с поставленной целью мы определили следующие задачи.

- выявить характерные орнаментальные мотивы отделки войлока у ингушских мастеров;

- определить устойчивые стилевые особенности казахских узорных войлоков; 
- используя иконологический метод, провести сравнительно-сопоставительный анализ декоративной отделки войлочных изделий у ингушского и казахского народов;

- сопоставить технологию изготовления самобытных узорных ковров из войлока.

Мы предполагаем, что совпадают как техника изготовления войлочных ковров, так и наиболее архаичные элементы их узорного оформления. Элементы орнамента, устойчиво повторяющиеся в декоре, помогают не только раскрыть мировоззренческую модель этноса, но и проследить исторически обусловленные компоненты его формирования.

Традиционная эстетика раннефеодальных обществ находит отражение в культовых символах, запечатленных в произведениях народного искусства. Композиция отделки различных изделий декоративно-прикладного творчества тюркских народов часто включает многолучевую солярную розетку. Она фиксируется в оформлении образцов традиционных видов ремесел, в том числе войлоковаляния. Розетки украшают как современные казахские войлочные ковры, так и - созданные мастерами прошлых столетий [16]. Указанный факт свидетельствует о преемственности эстетических принципов от поколения к поколению. Формы некоторых из розеток известны по памятникам периода Тюркских каганатов [12, с. 138]. Тюрки раннего средневековья, проживавшие на территориях современного Казахстана, почитали в качестве верховного божества само Небо (Тенгри), считая солнце его воплощением. В декоративно-прикладном искусстве образом светила послужили солярные розетки [11, с. 144]. Этот культ получил распространение среди номадов Центральной Азии, в том числе у праболгарских племен, свидетельствуя об общности взглядов на мироустройство $[13$, с. 28]. Религиозно-идеологические параллели обнаруживаются в культуре гуннов на Северном Кавказе, унаследовавших поклонение сармато-аланскому богу-солнцу, соединившемуся в их представлениях с Великим Тенгри. Учеными установлено сходство, как верований, так и архаических обрядов у ранних центральноазиатских тюркских и у северо-кавказских гунно-болгарских племен [1, с. 16]. Указанное явление нашло отражение в форме визуальных символов декоративно-прикладного искусства и наблюдается в творчестве дальних потомков. Аналогии обнаруживаются в орнаментальной системе ингушского и казахского войлочного ковроделия на этапе XX - начала XXI в.

\section{Основная часть}

Войлоковаляние, тесно связанное с условиями жизнеустройства, издавна выделялось в декоративно-прикладном творчестве ингушского и казахского народов. Наиболее распространенными у ингушей являлись самобытные войлочные ковры «истинги», привлекавшие внимание исследователей с начала XX в. Известны зарисовки декора войлоков, сделанных художником Х.Б. Ахриевым (1895-1940) в 1920-х гг. [15]. Войлоковаляние, как вид домашних занятий ингушских мастериц изучали этнографы в рамках, организованных государством, научных экспедиций 1930-х гг. [5, с. 57]. Собранные в их процессе старинные истинги хранились в музейных коллекциях г. Грозного и были утрачены в результате военных действий и грабежей периода военных конфликтов (1992 г.). Облик традиционных ковров-истингов прошлых столетий был зафиксирован в книге «Истинг», изданной турецким издательством (на турецком языке) в 2015 г. [6, с. 119]. Эти войлочные изделия сохранились до настоящего времени, т.к. оказались вывезенными членами мусульманской общины Кавказа в XIX в. Среди современных исследований искусства войлока ингушского народа выделяются труды 3. М.-Т. Дзахаровой, доктора исторических наук и мастера по изготовлению истингов [5; 6].

Образцы казахского художественного войлоковаляния изучались этнографами М.С. Мукановым (1981) [9], Х.А. Аргынбаевым (1987) и др. [1], историками и искусствоведами, среди которых пользуются известностью труды Асановой [2]. Она раскрывает семантическое значение часто встречающихся элементов орнамента, следующим образом: круг - солнце, свастика или вихревая розетка - движение солнца.

В своем исследовании мы опирались на труды вышеуказанных предшественников. Фактологическим материалом для нас послужили образцы войлоковаляния, хранящиеся в коллекциях таких музеев как: Ингушский государственный музей краеведения им. T.Х. Мальсагова (г. Назрань) и Центральный государственный музей Республики Казахстан (г. Алматы). Для выявления стилевых особенностей декора мы сопоставляли оформление войлочных ковров с орнаментом, сохранившимся в отделке более ранних соответствующих артефактов ингушского и казахского народного искусства. При определении общих и отличительных особенностей узоров отделки войлочных изделий с целью типологии, использовался сравнительно-исторический метод. Для определения веками сохраняющихся устойчивых элементов орнамента, переходящих от одного поколения мастеров к другому, применялся иконологический метод.

Художественное ремесло войлоковаляния у ингушей и казахов издревле считалось видом женского домашнего занятия. Войлочными коврами оформлялся интерьер жилища. Часть из них являлась напольными покрытиями, часть использовалась для сидений, самые искусные изделия вывешивались на стены. Материалом для изготовления служила овечья шерсть, отсортированная по цвету, очищенная от сора и распушенная. Из поколения в поколение передавались способы ее художественной обработки [14, с. 106; 17, с. 24].

Многовековое искусство войлока у ингушского народа отличалось локальными стилевыми особенностями. Натуральные красители применялись для придания войлоку сдержанных красноватых, оранжевых и коричневых оттенков. Декор в основном выполнялся в мозаичной технике следующим образом: из двух сложенных войлочных кусков различных цветов (как правило, светлого и темного тонов) вырезались узорные формы. С изнаночной стороны вырезанные элементы аккуратно сшивались, с лицевой стороны по лини шва 
накладывался шнур, подчеркивающий абрис декора. Получалась композиция, в которой контрастные по цвету элементы одинаковых форм накладывались на соответствующее поле по принципу зеркальной симметрии. При этом орнамент и его фон создавали как бы двойной узор. Таким образом, бордюром оформлялась по периметру широкая полоса ковра. Противоположные стороны ковра были асимметричными по цвету. Центральное поле декорировалось иным способом здесь обнаруживался четко выраженный центр, основной орнамент выделялся на однотонном фоне [6, с. 57]. Сходная технология наблюдается в работе казахский войлочниц. Мастерицы, изготавливая сырмак, складывали светлую и темную части. По заранее намеченному контуру прорезали узоры, таким образом, получались две равных композиции с противоположными по цвету, но одинаковыми по форме элементами орнамента. Их сшивали встык, закрывая шов шнуром. Симметричные бордюры обрамляли центральное поле изделия [17, с. 195].

В оформлении истингов часто применялся такой устойчивый орнаментальный элемент как свастика или завихренная розетка. Благодаря принципу преемственности указанная форма, олицетворяющая движение солнца по небосводу сохранялась веками и воспроизводилась не только в войлочных изделиях, но и в отделке экстерьера средневековых каменных строений (X-XVI) Ингушетии [5, с. 109]. Подобные орнаментальные мотивы, связанные с культом солнца наблюдаются в декоративно-прикладном искусстве тюркских народов [4], обнаруживаясь в древнем узорном оформлении войлочных изделий $[10$, с. 132,150$]$. В узорной резьбе по камню, дереву, а также вышивке - образ солнца часто запечатлен в виде многолепестковой солярной розетки [18, с. 164], которые большинство специалистов связывают с культом Тенгри, верховного бога номадов Азии [12, с. 147]. Кочевые племена Центральной Азии представляли собой историко-культурную общность, сохранявшуюся на протяжении многих тысячелетий, в любом месте их обитания [8, с. 263]. Их верховным богом считался Тенгри (небо), поклонение которому совпадало с культом Тенгри-хана в «царстве гуннов», проживающих на Северном Кавказе
[7, с. 266]. Указанное сходство можно объяснить либо существованием типологических параллелей, либо культурных влияний или сохранением генетических импульсов.

К устойчивым мотивам орнамента, связанным с природой, относится образ древа жизни. Почитание священного дерева обнаруживается в культуре многих народов. Оно олицетворяло собой трехчастную модель мироздания: верхние ветви служили местом обитания птиц и божеств, в густой кроне среднего уровня располагались живые люди. Души умерших находились в нижней части корней [3]. Стилизованное изображение древа жизни обнаруживается в декоре образцов, как художественного творчества прошлых столетий, так и в произведениях декоративно-прикладного искусства настоящего времени. Условный образ древа жизни часто занимал центральное поле традиционных ингушских ковров-истингов [14]. В тюркском искусстве древо жизни редко наблюдается как целое изображение, гораздо чаще применяется прием воспроизведения его отдельных частей: листьев, ветвей, плодов [4, с. 148].

\section{Заключение}

В культурах как ингушского, так и казахского народов сформировалось бережное отношение к войлоковалянию, связанному с национальной самоидентификацией. Схожие технологии создания войлочных ковров занимали много времени и являлись трудоемкими, но оставались неотъемлемой частью самобытного художественного творчества. Войлочные ковры обрели значение неразрывной связи с национальными культурными истоками, и в настоящее время, служат символом единства поколений. В декоре самобытных ингушских ковров наблюдаются такие мотивы орнамента, как солярные знаки и древо жизни. Аналогии обнаруживаются в оформлении образцов войлочных ковров у казахов и других тюркских народов, что свидетельствует о взаимопроникающих культурных контактах. Таким образом, узорные войлоки несут информативную функцию об исторических связях народов Азии и Кавказа.

\section{Список литературы}

1. Ажигали С.Е. Казахская этнографическая школа второй половины XX века // XIII Конгресс антропологов России: сб. материалов (Казань, 2-6 июля 2019 г.). - Москва; Казань: ИЭА РАН, КФУ. Институт истории им. Ш. Марджани АН РТ, 2019. - $516+$ LV c.

2. Асанова Б.Е. Казахский художественный войлок как феномен кочевой культуры: дис. ... канд. ист. наук. Алматы, 2009. - 38 с.

3. Березкин Ю.Е. Мифологические деревья в лесу культуры // Этнографическое обозрение. - 2012. №6. - С. 3-18.

4. Валеев Ф.Х. Татарский народный орнамент / Казань: Таткнигоиздат, 2002. - 295 с.

5. Дзахарова 3.М.-Т. Национальное самосознание ингушей: этнокультурные факторы. - Назрань: Пилигрим, 2015. - $213 \mathrm{c.}$

6. Дзахарова 3. М.-Т. Войлочное орнаментальное ковроделие у ингушей // Вестник Ингушского научно-исследовательского института гуманитарных наук им. Ч.Э. Арзиева. - 2017. - №1. - 168 с.

7. Гмыря Л.Б. Гунны на Северном Кавказе // История татар с древнейших времен: в 7-и томах. Т. I: Народы степной Евразии в древности. - Казань: Рухият, 2002. - 552 с.

8. Кляшторный С.Г. Степная империя тюрков и ее наследники // История татар с древнейших времен: в 7-и томах. T. I: Народы степной Евразии в древности. - Казань: Рухият, 2002. - 552 с.

9. Муканов М.С. Казахские домашние художественные ремесла. - Алма-Ата: Казахстан, 1979. - 120 с. 
10. Царева Е.Г. Войлоки Евразии // Культурное наследие народов Центральной Азии, Казахстана и Кавказа. СПб.: Наука, 2006. - С. 226-265.

11. Полосьмак Н.В. Костюм и текстиль пазырыкцев Алтая (IV-III вв. до н.э.) / Н.В. Полосьмак, Л.Л. Баркова. - Новосибирск: Инфолио, 2005. - 232 с.

12. Руденко С.И. Древнейшие в мире художественные ковры и ткани из оледенелых курганов Горного Алтая. - М.: Искусство, 1968. - 136 с.

13. Савинов Д.Г. Народы Южной Сибири в древнетюркскую эпоху. - Л., 1984. - 186 с.

14. Студенецкая Е.Н. Узорные войлоки Кавказа (в свете исторических связей народов Кавказа и Азии) // Советская этнография. - 1979. - №1. - С. 105-115.

15. Татаев В.А. Декоративно-прикладное искусство Чечено-Ингушетии / В.А. Татаев, Н.Ш. Шабаньянц. Грозный: Чеч.-Инг. кн. изд-во, 1974. - 18 с.

16. Тохтабаева Ш.Ж. Шедевры Великой степи. - Алматы: Дайк-Пресс, 2008. - 240 с.

17. Октябрьская И.В. Традиционные войлоки казахов и современное ковроделие / И.В. Октябрьская, З.К. Сураганова, С.К. Сураганов // Историко-культурное наследие. Краеведение. - С. 189-199.

18. Шкляева Л.М. Стилевые особенности золотного шитья у татар-мишарей Ульяновской области // Обсерватория культуры. -2020 . - Т. 17, №2. - С. 140-150.

\section{References}

1. Azhigali, S. E. (2019). Kazakhskaia etnograficheskaia shkola vtoroi poloviny XX veka. XIII Kongress antropologov Rossii, . Moskva;; Mardzhani AN RT.

2. Asanova, B. E. (2009). Kazakhskii khudozhestvennyi voilok kak fenomen kochevoi kul'tury., 38. Almaty.

3. Berezkin, Iu. E. (2012). Mifologicheskie derev'ia v lesu kul'tury. Etnograficheskoe obozrenie, 6, 3-18.

4. Valeev, F. Kh. (2002). Tatarskii narodnyi ornament., 295. Kazan': Tatknigoizdat.

5. (2015). Dzakharova Z.M.-T. Natsional'noe samosoznanie ingushei., 213. Nazran': Piligrim.

6. Dzakharova, Z. (2017). M.-T. Voilochnoe ornamental'noe kovrodelie u ingushei. Vestnik Ingushskogo nauchnoissledovatel'skogo instituta gumanitarnykh nauk im. Ch.E. Arzieva, 1, 168.

7. Gmyria, L. B. (2002). Gunny na Severnom Kavkaze. Istoriia tatar s drevneishikh vremen: v 7-i tomakh. T. I: Narody stepnoi Evrazii v drevnosti, 552. Kazan': Rukhiiat.

8. Kliashtornyi, S. G. (2002). Stepnaia imperiia tiurkov i ee nasledniki. Istoriia tatar s drevneishikh vremen: $\mathrm{v} 7-\mathrm{i}$ tomakh. T. I: Narody stepnoi Evrazii v drevnosti, 552. Kazan': Rukhiiat.

9. Mukanov, M. S. (1979). Kazakhskie domashnie khudozhestvennye remesla., 120. Alma-Ata: Kazakhstan.

10. Tsareva, E. G. (2006). Voiloki Evrazii. Kul'turnoe nasledie narodov Tsentral'noi Azii, Kazakhstana i Kavkaza, 226-265. $\mathrm{SPb} .:$ Nauka.

11. Polos'mak, N. V., \& Barkova, L. L. (2005). Kostium i tekstil' pazyryktsev Altaia (IV-III vv. do n.e.)., 232. Novosibirsk: Infolio.

12. Rudenko, S. I. (1968). Drevneishie v mire khudozhestvennye kovry i tkani iz oledenelykh kurganov Gornogo Altaia., 136. M.: Iskusstvo.

13. Savinov, D. G. (1984). Narody Iuzhnoi Sibiri v drevnetiurkskuiu epokhu., 186. L.

14. Studenetskaia, E. N. (1979). Uzornye voiloki Kavkaza (v svete istoricheskikh sviazei narodov Kavkaza i Azii). Sovetskaia etnografiia, 1, 105-115.

15. Tataev, V. A., \& Shaban'iants, N. Sh. (1974). Dekorativno-prikladnoe iskusstvo Checheno-Ingushetii., 18. Groznyi: Chech.-Ing. kn. izd-vo.

16. Tokhtabaeva, Sh. Zh. (2008). Shedevry Velikoi stepi., 240. Almaty: Daik-Press.

17. Oktiabr'skaia, I. V., Suraganova, Z. K., \& Suraganov, S. K. Traditsionnye voiloki kazakhov i sovremennoe kovrodelie. Istoriko-kul'turnoe nasledie. Kraevedenie, S. 189.

18. Shkliaeva, L. M. (2020). Stilevye osobennosti zolotnogo shit'ia u tatar-misharei Ul'ianovskoi oblasti. Observatoriia kul'tury, T. 17, 2, 140-150.

Информация об авторе

Бердникова Ольга Юрьевна - преподаватель МБОУ ДО «Детская художественная школа №5», аспирант Института языка, литературы и искусства им. Г. Ибрагимова Академии наук Республики Татарстан, Казань, Российская Федерация.

\section{Information about the author}

Olga Yu. Berdnikova - teacher MBEI of PE of Kazan "Child School of Art No. 5", postgraduate student of Institute of language, literature and arts named after G. Ibragimov of Tatarstan Academy of Sciences, Kazan, Russian Federation.

Поступила в редакцию / Received 22.12.2020

Принята к публикации / Accepted 17.06.2021

Опубликована / Published 25.06.2021 